\title{
The prognostic significance of anti-angiogenesis therapy in ovarian cancer: a meta-analysis
}

\author{
Jun $\mathrm{Li}^{1,2,3}$, Shufen $\mathrm{Li}^{4}$, Ruifang Chen ${ }^{1,2,3}$, Hailin $\mathrm{Yu}^{1}$ and $\mathrm{Xin} \mathrm{Lu}^{1,2,3,5^{*}}$
}

\begin{abstract}
Objective: The prognostic value of anti-angiogenesis therapy in ovarian cancer patients is currently under debate. In this study, we assessed the effects of anti-angiogenesis therapy on the progression free survival (PFS) and overall survival (OS) of ovarian cancer patients.
\end{abstract}

Materials and methods: PubMed was searched to identify relevant studies that evaluated the therapeutic value of anti-angiogenic agents in ovarian cancer (the final search was current to Dec. 13th 2014). Reviews of each study were conducted, and the data were extracted. The primary outcomes that were analysed were progression free survival (PFS) and overall survival (OS). The pooled hazard ratio (HR) and $95 \%$ confidence intervals (Cls) were calculated using the random and fixed-effects models, and subgroup and sensitivity analyses were subsequently performed.

Results: A total of 12 studies were included in the meta-analysis. The overall analysis revealed that the incorporation of anti-angiogenesis therapy was significantly associated with a longer PFS ( $\mathrm{HR}, 0.66 ; 95 \% \mathrm{Cl}, 0.58-0.75 ; \mathrm{P}<0.01)$ and a longer OS ( $\mathrm{HR}, 0.89 ; 95 \% \mathrm{Cl}, 0.82-0.97 ; P=0.01)$ in the total population, and these findings were confirmed by one-way sensitivity analyses. Further subgroup analyses demonstrated that the administrations of each of the agents were associated with improved PFSs. The prognostic value of anti-angiogenesis therapy for the OS was significant in the trebananib subgroup ( $\mathrm{HR}, 0.81 ; 95 \% \mathrm{Cl}, 0.67-0.99 ; P=0.04)$. The bevacizumab subgroup exhibited a similar trend that did not reach statistical significance ( $\mathrm{HR}, 0.90 ; 95 \% \mathrm{Cl}, 0.80-1.01 ; P=0.08)$.

Conclusions: The present meta-analysis indicated that anti-angiogenesis therapy in ovarian cancer patients was associated with a better clinical outcome. Further studies are warranted to identify the specific subgroup of patients who are most likely to benefit from anti-angiogenesis therapy.

Keywords: Ovarian cancer, Anti-angiogenesis therapy, Prognosis, Meta-analysis

\section{Background}

Worldwide, approximately 238,000 women are diagnosed with ovarian cancer and 151,000 women succumb to this disease in 2012. Currently, the standard treatment for ovarian cancer is aggressive cytoreductive surgery, followed by a platinum and taxane combination chemotherapy [1]. Although $70 \%$ of the patients will experience a complete clinical remission after the initial therapy, the majority will eventually experience a cancer progression and succumb to their disease [2]. Thus, ovarian cancer patients usually

\footnotetext{
*Correspondence: xinludoc@163.com

'Obstetrics and Gynecology Hospital, Fudan University, Shanghai 200011, China 2Department of Obstetrics and Gynecology of Shanghai Medical College, Fudan University, Shanghai 200032, China

Full list of author information is available at the end of the article
}

require further treatments. With the aim of improving the prognoses of ovarian cancer patients, multiple clinical trials have been conducted to explore new therapies, including anti-angiogenesis therapy [3].

Angiogenesis is a complex, multi-step process that is controlled by several key pathways, including the vascular endothelial growth factor (VEGF) pathway, the plateletderived growth factor (PDGF) pathway, the fibroblast growth factor (FGF) pathway, and the angiopoietin-Tie2 receptor pathway [4]. Accumulating evidence has demonstrated that the disruption of the angiogenesis axis is involved in the progression of ovarian cancer via the promotion of tumor growth, ascites, and metastases [5]. Due to these findings, anti-angiogenesis therapy has been 
extensively studied in patients with ovarian cancer $[6,7]$. Promisingly, extended progression free survival (PFS) has been observed in patients who receive antiangiogenesis therapy. However, it is not appropriate to simplify the clinical benefit of new drugs to improvements in PFS, and overall survival (OS) is also a key secondary study endpoint. Moreover, the OS benefit of anti-angiogenesis therapy remains controversial. To acquire improved better insight into the clinical benefits of anti-angiogenesis therapy for ovarian cancer, we performed a meta-analysis of the published literature on this topic. Specifically, we assessed the prognostic value of anti-angiogenesis therapy for the PFS and OS of ovarian cancer patients.

\section{Methods}

We designed, analysed, and reported our meta-analysis according to the PRISMA Statement guidelines.

\section{Search strategy}

A literature search (the final search was current to Dec. 13th, 2014) of PubMed for articles addressing the clinical benefit of anti-angiogenesis therapy in ovarian cancer was performed using the following keywords: (bevacizumab OR trebananib OR pazopanib OR cediranib OR nintedanib OR imatinib OR perifosine OR sorafenib OR sunitinib OR AEE788 OR aflibercept OR "AMG 386" OR "BIBF 1120") AND ("ovarian cancer" OR "ovarian neoplasm" OR "ovarian tumor" OR "ovarian carcinoma"). The results were limited to peer-reviewed, English language reports. Abstracts from ASCO, ESMO and ESGO were also screened to identify the potentially relevant studies. Additionally, the references lists of the retrieved articles were examined for potentially eligible studies.

\section{Eligibility criteria}

The studies were deemed eligible for inclusion in the meta-analysis based on the following criteria: (i) either the PFS or the OS benefit of anti-angiogenesis therapy in ovarian cancer patients was reported or could be extrapolated from reported data, and (ii) only randomized clinical trials were included. Additionally, we scrutinized all of included articles to avoid the potential influence of redundant studies.

\section{Data extraction}

The data extracted for this meta-analysis included the first author, anti-angiogenic agents, journal, phase, year, treatment settings, and hazard ratios (HRs) for the PFS and OS.

\section{Statistical analysis}

Briefly, the HRs and their respective $95 \%$ CI were used to assess the prognostic effect of anti-angiogenesis therapy for ovarian cancer patients. The pooled HRs for the PFS and OS were evaluated with fixed or random-effects models. The potential heterogeneity between studies was estimated using the Cochran's Q-test and the $\mathrm{I}^{2}$ index. A fixed-effects model was used employed when the $\mathrm{I}^{2} \leq 50 \%$; otherwise, a random-effects model was used. Publication bias was assessed with Egger's and Begg's test. Additionally, one-way sensitivity analyses were performed to evaluate the effects of the individual studies by estimating the average HRs in the absence of each study. All analyses were performed with STATA 11.0 software.

\section{Results}

\section{Identification and characteristics of relevant studies}

We screened 485 potentially relevant articles in our systematic literature search and identified 10 eligible studies (Fig. 1). Two additional reports presented at the 2013 ESMO meeting and the 2013 ESGO biennial meeting were also included in our meta-analysis (Fig. 1). The characteristics of the included studies are shown in Table 1 [8-19].

\section{The effects of anti-angiogenesis therapy on PFS and OS}

The PFS HRs were available in 11 studies. The estimated pooled HR revealed that the incorporation of anti-angiogenesis therapy was associated with an improved PFS in ovarian cancer patients (HR, 0.66; $95 \%$ CI, 0.58-0.75; $P<0.01$; random effects; Fig. 2a). The heterogeneity between the studies was significant $\left(P=0.00, \mathrm{I}^{2}=76.4 \%\right)$. There was no significant publication bias $\left(\mathrm{P}_{\mathrm{Begg}}=0.30 ; \mathrm{P}_{\text {Egger }}=0.17\right)$.

The HRs for OS were available in 10 studies. The estimated pooled HR showed that anti-angiogenesis therapy contributed to improved OS in ovarian cancer patients (HR, 0.89; $95 \% \mathrm{CI}, 0.82-0.97 ; P=0.01$; fixed effects; Fig. 2b). No significant heterogeneity was detected among studies $\left(P=0.514, \mathrm{I}^{2}=0.0 \%\right)$. There was no significant publication bias $\left(\mathrm{P}_{\text {Begg }}=0.53 ; \mathrm{P}_{\text {Egger }}=0.21\right)$.

Our results were further confirmed by one-way sensitivity analysis (Fig. 3a, b).

\section{Subgroup analyses of anti-angiogenesis in ovarian cancer}

Subgroup analyses stratified by the anti-angiogenesis agents indicated that administrations of each of the agents were associated with improved PFS (Fig. 4a). The prognostic value of anti-angiogenesis therapy for OS was significant in the trebananib subgroup (HR, 0.81; $95 \%$ CI, $0.67-0.99 ; \quad P=0.04 ;$ fixed effects; Fig. $4 \mathrm{~b})$. The bevacizumab subgroup exhibited a similar trend that did not reach statistical significance (HR, 0.90; $95 \% \mathrm{CI}$, 0.80-1.01; $P=0.08$; fixed effects; Fig. 4b).

Moreover, the clinical benefit of anti-angiogenesis therapy differed between the patients with primary ovarian cancer and the patients with recurrent ovarian 


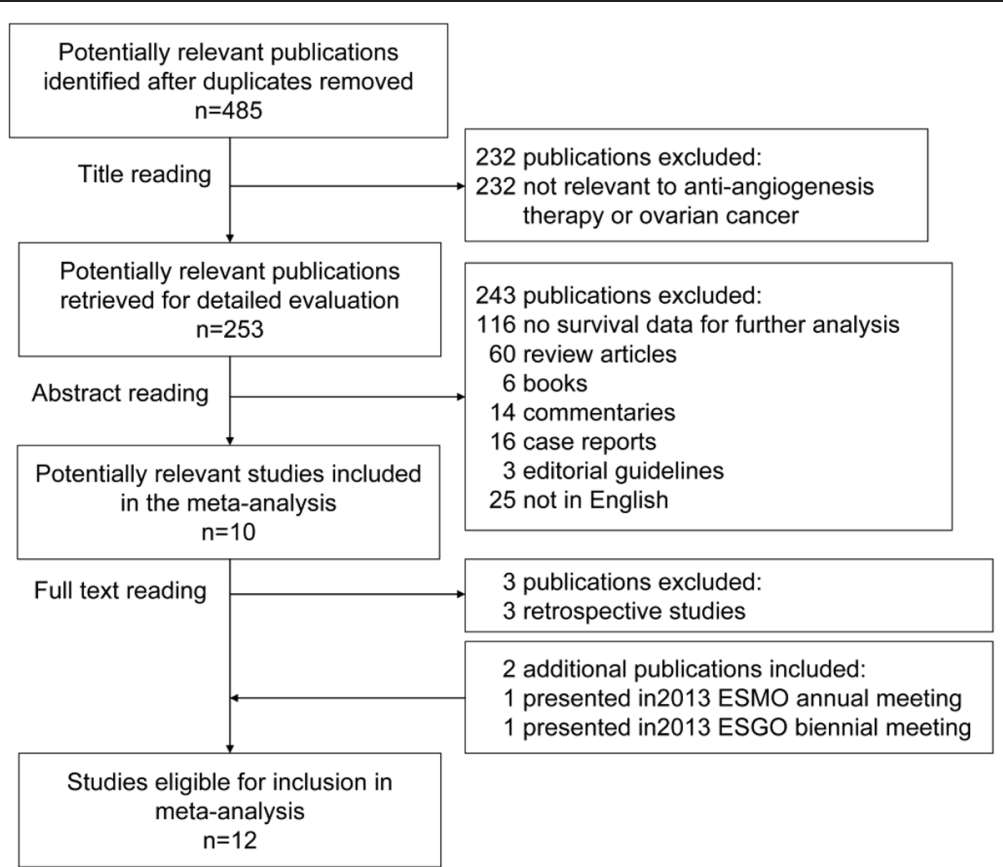

Fig. 1 Flow chart of the search strategy used for the selection of eligible studies

cancer. Specifically, improved PFS was observed in both recurrent setting ( $\mathrm{HR}, 0.58$; $95 \% \mathrm{CI}, 0.50-0.67 ; P=0.02$; random effects; Fig. 5a) and primary setting (HR, 0.78; $95 \%$ CI, 0.68-0.89; $P=0.01$; random effects; Fig. 5a). However, the prognostic value of anti-angiogenesis therapy for OS was significant in the patients with recurrent ovarian cancer (HR, 0.85; 95 \% CI, 0.76-0.96; $P=0.01$; fixed effects; Fig. 5b), but not in the primary setting (HR, 0.94; $95 \%$ CI, 0.83-1.07; $P=0.35$; fixed effects; Fig. 5b).

\section{Discussion}

Angiogenesis has been implicated in the pathogenesis and progression of ovarian cancer potentially due to the promotion of tumor growth, ascites, and metastases [5]. Therefore, therapies based on angiogenesis-specific pathway are being extensively studied in ovarian cancer $[6,7]$. Our present meta-analysis was based on a pool of 8 phase III and 4 phase II clinical trials and thus differed from the two existing meta-analyses, which included only clinical trials involving bevacizumab [20, 21]. Namely, these two meta-analyses indicated that the addition of bevacizumanb to chemotherapy led to significant improvement in PFS and also increased the occurrence of adverse events including gastrointestinal events, hypertension, proteinuria, and aterial thromboembolism [20, 21]. The present meta-analysis revealed that the incorporation of anti-angiogenesis therapy was significantly associated with improvements in PFS and OS of ovarian cancer patients. The pooled findings were further confirmed by one-way sensitivity analyses. More interestingly, the subgroup analyses revealed that the patients with recurrent ovarian cancer derived greater OS benefit from the anti-angiogenesis agents. In contrast, anti-angiogenesis therapy in the primary setting conferred no significant OS benefit to ovarian cancer patients. These pooled results do not indicate that the recurrence setting is ideal for the incorporation of antiangiogenesis into the treatment of ovarian cancer. In the front-line setting, although the ICON7 and GOG218 trial failed to identify significant differences in the OS benefits for patients according to whether bevacizumab was added to the treatment across the entire populations of those studies, the addition of bevacizumab to front line therapy does confer an OS improvement for patients who are at a high risk for progression $[10,11]$. This finding raised a question regarding patient selection that that led to the use of individualized treatment regimens. Unfortunately, there is still a paucity of reliable biomarkers to predict the clinical benefit of anti-angiogenesis therapy [22]. This paucity inspired us to identify specific biomarker signatures that can be used to stratify patients with ovarian cancer according to the expected benefit of anti-angiogenesis therapy [22, 23]. Possible serum biomarkers including mesothelin, FLT4, AGP, and CA-125 were investigated [24]. Additionally, the utilities of adiposity measurements and dynamic contrast-enhanced magnetic resonance imaging (DCE-MRI) results as clinical biomarkers for anti-angiogenesis therapy are also currently under investigation [25, 26]. More recently, miR-378 and its downstream targets, ALCAM and EHD1, 
Table 1 Characteristics of included studies

\begin{tabular}{|c|c|c|c|c|c|c|c|c|c|c|c|c|}
\hline \multirow[t]{2}{*}{ First author } & \multirow[t]{2}{*}{ Agents } & \multirow[t]{2}{*}{ Journal } & \multirow[t]{2}{*}{ Phase } & \multirow[t]{2}{*}{ Year } & \multirow[t]{2}{*}{$\begin{array}{l}\text { Treatment } \\
\text { setting }\end{array}$} & \multicolumn{2}{|l|}{ No. of patients } & \multicolumn{2}{|c|}{$\begin{array}{l}\text { Median follow-up } \\
\text { time (months) }\end{array}$} & \multirow[t]{2}{*}{$\begin{array}{l}\text { FIGO } \\
\text { stage }\end{array}$} & \multicolumn{2}{|c|}{ Hazard ratio $(95 \% \mathrm{Cl})$} \\
\hline & & & & & & Control group & $\begin{array}{l}\text { Anti-angiogenic } \\
\text { group }\end{array}$ & $\begin{array}{l}\text { Control } \\
\text { group }\end{array}$ & $\begin{array}{l}\text { Anti-angiogenic } \\
\text { group }\end{array}$ & & PFS & OS \\
\hline Pujade-Lauraine E [8] & Bevacizumab & $\mathrm{JCO}$ & III & 2014 & Recurrent & 182 & 179 & 13.9 & 13 & - & $0.48(0.38-0.60)$ & $0.85(0.66-1.08)$ \\
\hline Aghajanian C [9] & Bevacizumab & $\mathrm{JCO}$ & III & 2012 & Recurrent & 242 & 242 & 24 & 24 & - & $0.48(0.39-0.61)$ & $1.03(0.79-1.33)$ \\
\hline Perren TJ [10] & Bevacizumab & NEJM & III & 2011 & Primary & 764 & 764 & 19.4 & 19.4 & I-IV & $0.87(0.77-0.99)$ & $0.85(0.69-1.04)$ \\
\hline Burger RA [11] & Bevacizumab & NEJM & III & 2011 & Primary & 625 & 623 & 17.4 & 17.4 & III-IV & $0.64(0.55-0.76)$ & $0.92(0.73-1.15)$ \\
\hline Monk BJ [12] & Trebananib & Lancet Oncology & III & 2014 & Recurrent & 458 & 461 & 10.1 & 10.1 & - & $0.66(0.57-0.77)$ & $0.86(0.69-1.08)$ \\
\hline Karlan BY [13] ${ }^{\mathrm{a}}$ & Trebananib & $\mathrm{JCO}$ & $\|$ & 2012 & Recurrent & 55 & 53 & 14.9 & 15.4 & I-IV & $0.81(0.51-1.30)$ & $0.60(0.34-1.06)$ \\
\hline Karlan BY [13] & Trebananib & $\mathrm{JCO}$ & $\|$ & 2012 & Recurrent & 55 & 53 & 14.9 & 15.2 & I-IV & $0.75(0.49-1.21)$ & $0.77(0.45-1.31)$ \\
\hline du Bois A [14] & Pazopanib & $\mathrm{JCO}$ & III & 2014 & Primary & 468 & 472 & 24 & 24 & II-IV & $0.77(0.64-0.91)$ & $1.08(0.87-1.33)$ \\
\hline Liu JF [15] & Cediranib & Lancet Oncology & $\|$ & 2014 & Recurrent & 46 & 44 & 16.6 & 16.6 & - & $0.42(0.23-0.76)$ & - \\
\hline Ledermann JA [16] & Cediranib & 2013 ESMO meeting & III & 2013 & Recurrent & - & - & - & - & - & $0.57(0.45-0.74)$ & $0.70(0.51-0.99)$ \\
\hline Ledermann JA [17] & Nintedanib & JCO & $\|$ & 2011 & Recurrent & 40 & 43 & - & - & I-IV & $0.65(0.41-1.02)$ & $0.84(0.51-1.39)$ \\
\hline du Bois A [18] & Nintedanib & 2013 ESGO meeting & III & 2013 & Primary & 455 & 911 & - & - & IIB-IV & $0.84(0.72-0.98)$ & - \\
\hline Gotlieb WH [19] & Aflibercept & Lancet Oncology & $\|$ & 2012 & Recurrent & 26 & 29 & - & - & - & - & $1.01(0.56-1.86)$ \\
\hline
\end{tabular}

${ }^{\mathrm{a}}$ Trebananib:10mg/kg; ${ }^{\mathrm{b}}$ Trebananib:3mg/kg 
a Study

ID
$\%$

HR (95\% Cl) Weight

$0.48(0.38,0.60) \quad 9.19$

$0.48(0.39,0.61) \quad 9.33$

$0.87(0.77,0.99) \quad 11.34$

$0.64(0.55,0.76) \quad 10.71$

$0.66(0.57,0.77) \quad 10.87$

$0.81(0.51,1.30) \quad 4.92$

$0.75(0.49,1.21) \quad 5.13$

$0.77(0.64,0.91) \quad 10.34$

$0.42(0.23,0.76) \quad 3.55$

$0.57(0.45,0.74) \quad 8.75$

$0.65(0.41,1.02) \quad 5.08$

$0.84(0.72,0.98) \quad 10.79$

$0.66(0.58,0.75) \quad 100.00$

Overall (I-squared $=76.4 \%, p=0.000$ )

NOTE: Weights are from random effects analysis

$\begin{array}{lll}.23 & 1 & 4.35\end{array}$

b Study

ID

Pujade-Lauraine E [8]

Aghajanian C [9]

Perren TJ [10]

Burger RA [11]

Monk BJ [12]

Karlan BY* [13]

Karlan $B Y^{* *}$ [13]

du Bois A [14]

Ledermann JA [16]

Ledermann JA [17]

Gotlieb WH [19]

Overall (I-squared $=0.0 \%, p=0.514$ )
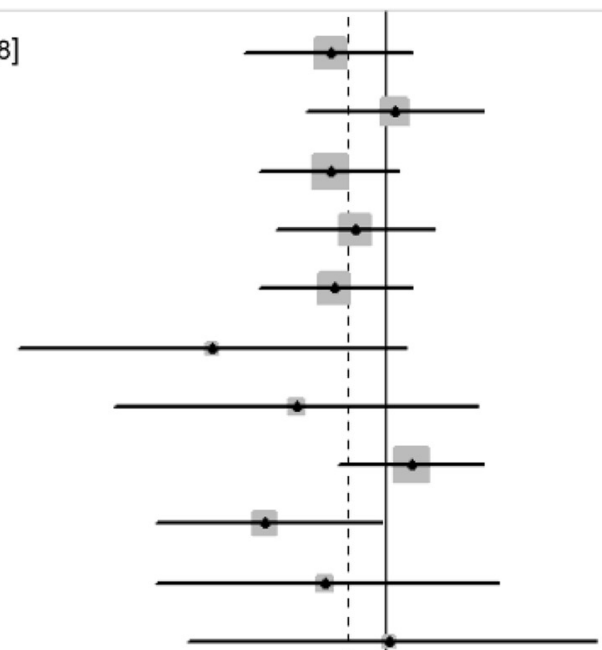

$\%$

HR $(95 \% \mathrm{Cl}) \quad$ Weight

$0.85(0.66,1.08) \quad 11.90$

$1.03(0.79,1.33) \quad 10.71$

$0.85(0.69,1.04) \quad 17.15$

$0.92(0.73,1.15) \quad 13.62$

$0.86(0.69,1.08) \quad 14.38$

$0.60(0.34,1.06) \quad 2.23$

$0.77(0.45,1.31) \quad 2.53$

$1.08(0.87,1.33) \quad 16.03$

$0.70(0.51,0.99) \quad 6.56$

$0.84(0.51,1.39) \quad 2.87$

$1.01(0.56,1.86) \quad 2.00$

$0.89(0.82,0.97) \quad 100.00$

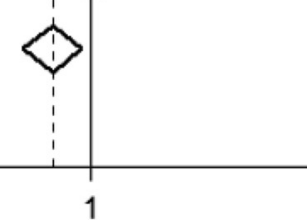

2.94

Fig. 2 Forest plots of the clinical benefit of anti-angiogenesis therapy in ovarian cancer. $\mathbf{a}$ The effects of anti-angiogenic agents on PFS; $\mathbf{b}$ The effects of anti-angiogenic agents on OS 
a

Meta-analysis estimates, given named study is omitted

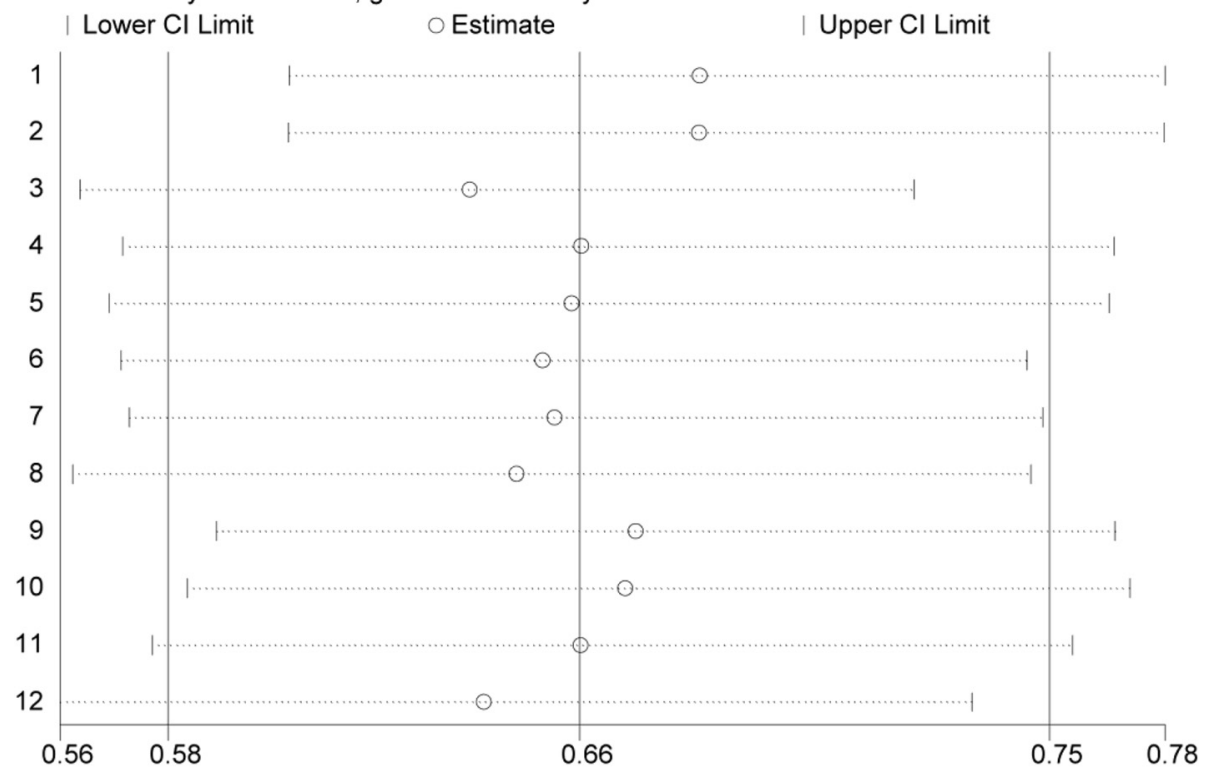

b

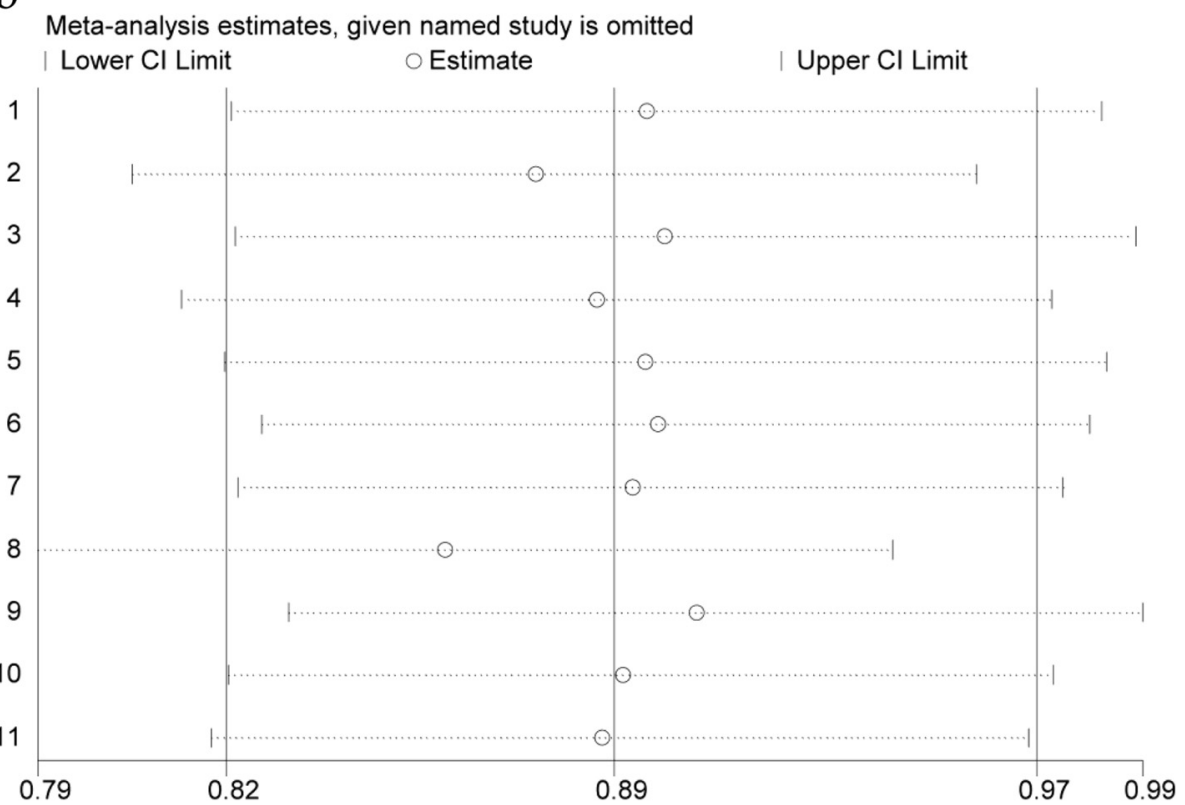

Fig. 3 Confirmation of the stability of our results via one-way sensitivity analyses. $\mathbf{a}$, b One-way sensitivity analyses confirmed the effects of anti-angiogenesis therapy on PFS (a) and OS (b)

have been proven to be potential biomarkers of the response to anti-angiogenic therapy in ovarian cancer [27]. The challenge ahead is to validate these biomarkers and implement their use in clinical practice with the goal of providing improved guidance regarding the use of antiangiogenic agents.

Another intriguing finding of present study is that trebananib seems to be active in the treatment of recurrent ovarian cancer. Improvements in both PFS and
OS were observed in the patients who were treated with trebananib in the recurrent setting. Another phase 3 trial assessing the potential benefit of trebananib in the recurrent setting is underway (TRINOVA-2; NCT01281254). Moreover, the clinical benefit of the addition of trebananib to front-line chemotherapy is also currently under investigation in a phase 3 study (TRINOVA-3; NCT01493505). Notably, the mechanism by which trebananib blocks angiogenesis and its associated 
a Study

$\mathrm{HR}(95 \% \mathrm{Cl})$

ID

$0.48(0.38,0.60)$

$0.48(0.39,0.61)$

$0.87(0.77,0.99)$

Pujade-Lauraine E [8]

Aghajanian C [9]

Perren TJ [10]

Burger RA [11]

Subtotal (l-squared $=90.9 \%, p=0.000)$

$0.61(0.45,0.81)$

Trebananib

Monk BJ [12]

Karlan $\mathrm{BY}^{*}[13]$

Karlan $B Y^{* *}[13]$

Subtotal (1-squared $=0.0 \%, p=0.648$ )

Pazopanib

du Bois A [14]

Subtotal $(\mid$-squared $=. \%, p=$.)

Cediranib

Liu JF [15]

Ledermann JA [16]

Subtotal $(I-$ squared $=0.0 \%, p=0.355)$

Nintedanib

Ledermann JA [17]

du Bois A [18]

Subtotal (l-squared $=8.4 \%, p=0.296)$

Overall (I-squared $=76.4 \%, p=0.000$ )

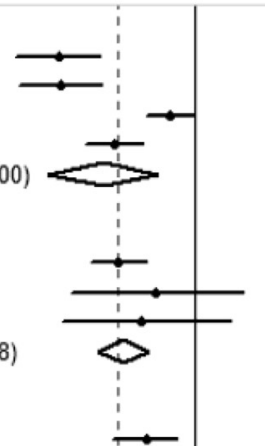

$0.66(0.57,0.77)$

$0.81(0.51,1.30)$

$0.75(0.49,1.21)$

$0.68(0.59,0.78)$

$0.77(0.64,0.91)$

$0.77(0.65,0.92)$

NOTE: Weights are from random effects analysis

$\begin{array}{lll}1 & & 1 \\ 23 & 1 & 4.35\end{array}$

b Study

ID

$\mathrm{HR}(95 \% \mathrm{Cl})$

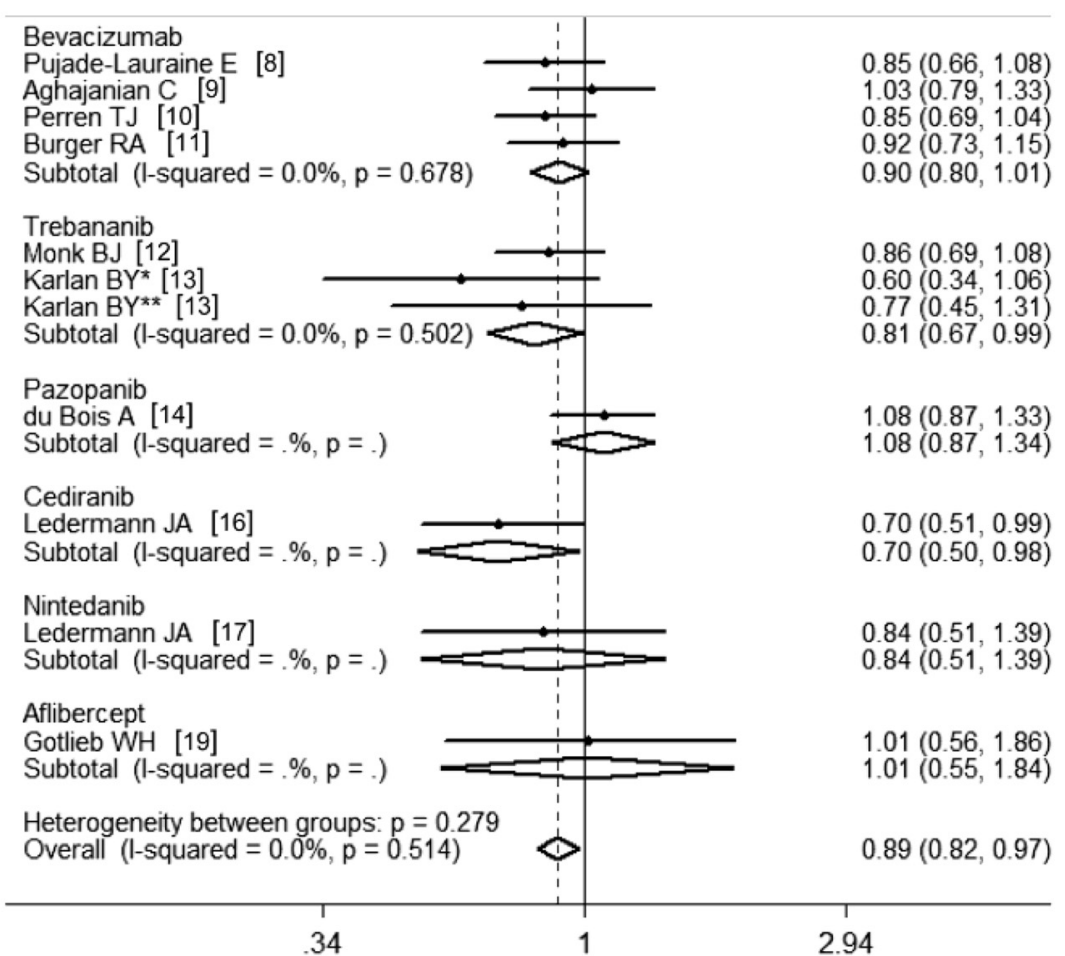

Fig. 4 Subgroup analyses stratified according to anti-angiogenic agents. a The effects of anti-angiogenic agents on PFS; (b) The effects of anti-angiogenic agents on OS 
a Study

ID

HR $(95 \% \mathrm{Cl})$

Recurrent

Pujade-Lauraine E [8]

Aghajanian C [9]

Monk BJ [12]

Karlan $B Y^{*}$ [13]

Karlan $B Y^{* *}$ [13]

Liu JF [15]

Ledermann JA [16]

Ledermann JA [17]

Subtotal (I-squared $=44.4 \%, p=0.083$ )

Primary

Perren TJ [10]

Burger RA [11]

du Bois A [14]

du Bois A [18]

Subtotal $($ I-squared $=67.6 \%, p=0.026$ )

Overall (I-squared $=76.4 \%, p=0.000$ )

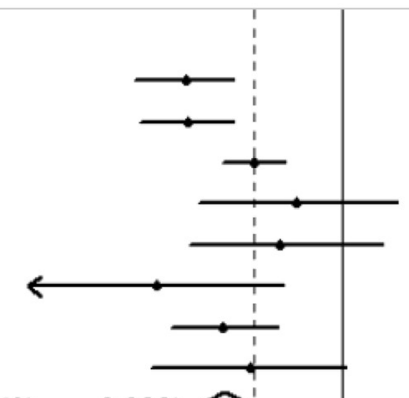

$0.48(0.38,0.60)$

$0.48(0.39,0.61)$

$0.66(0.57,0.77)$

$0.81(0.51,1.30)$

$0.75(0.49,1.21)$

$0.42(0.23,0.76)$

$0.57(0.45,0.74)$

$0.65(0.41,1.02)$

$0.58(0.50,0.67)$

NOTE: Weights are from random effects analysis !

$\begin{array}{lll}.23 & 1 & 4.35\end{array}$

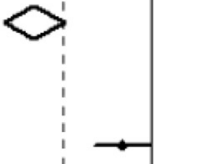

$0.87(0.77,0.99)$

$0.64(0.55,0.76)$

$0.77(0.64,0.91)$

$0.84(0.72,0.98)$

$0.78(0.68,0.89)$

$0.66(0.58,0.75)$

b Study

$\operatorname{HR}(95 \% \mathrm{Cl})$

\section{Recurrent}

Pujade-Lauraine E [8]

Aghajanian C [9]

Monk BJ [12]

Karlan BY* [13]

Karlan $B Y^{* *}$ [13]

Ledermann JA [16]

Ledermann JA [17]

Gotlieb WH [19]

Subtotal (l-squared $=0.0 \%, p=0.629$ )

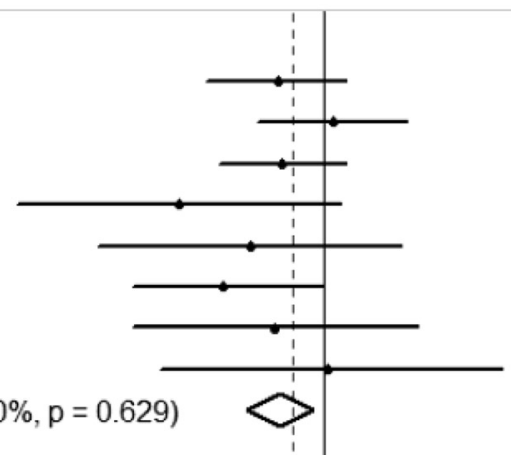

$0.85(0.66,1.08)$

$1.03(0.79,1.33)$

$0.86(0.69,1.08)$

$0.60(0.34,1.06)$

$0.77(0.45,1.31)$

$0.70(0.51,0.99)$

$0.84(0.51,1.39)$

$1.01(0.56,1.86)$

$0.85(0.76,0.96)$

Primary

Perren TJ [10]

Burger RA [11]

du Bois A [14]

Subtotal (l-squared $=23.6 \%, p=0.270$ )

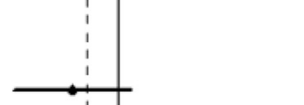

$0.85(0.69,1.04)$

$0.92(0.73,1.15)$

$1.08(0.87,1.33)$

$0.94(0.83,1.07)$

Heterogeneity between groups: $p=0.252$

Overall (l-squared $=0.0 \%, p=0.514$ )

$0.89(0.82,0.97)$

Fig. 5 Subgroup analyses stratified according to treatment settings. a The effects of anti-angiogenesis therapy of PFS stratified according to treatment setting; $\mathbf{b}$ The effects of anti-angiogenesis therapy on OS according to treatment settings 
toxicity profile are distinct from those of VEGF pathway inhibitors [12]. Thus, trebananib provides a non-VEGF anti-angiogenesis option for the treatment of ovarian cancer and raises the possibility that trebananib could be combined with the VEGF pathway inhibitors, e.g., bevacizumab, in the treatment of ovarian cancer.

Certain limitations must be considered when interpreting the pooled findings. First, our meta-analysis primarily focused on the PFS and OS. Indeed, the value of the PFS for assessing the clinical benefit of new drugs for ovarian cancer has been controversial. Additionally, it is not appropriate to simplify the clinical benefits of new drugs to improvements in OS, particularly when the OS benefit of a drug is marginal, but the side effects of that drug are life threatening. Thus, appropriately designed and executed randomized trials that consider the quality of life are needed [28]. Such trials should balance the efficacy, safety, toxicity and cost. Second, significant heterogeneity was found in our study. We deduced that variability in definitions of end point, measurements, experimental design, sample size, patient characteristics, and severity of the disease, may all represent a source of heterogeneity in our meta-analysis. Publication bias is another concern. We attempted to identify all of the relevant studies, but unavoidably, some studies could still be missing. As the additional high-quality clinical trials related to anti-angiogenesis therapy that are underway are completed, further analyses can be performed to validate the trends observed here.

\section{Conclusions}

The pooled results support the notion of a prognostic value of anti-angiogenesis therapy in ovarian cancer patients. The future challenge is to identify specific subgroups of patients who stand to benefit most to anti-angiogenesis therapy.

\section{Competing interests}

The authors declare that there are no competing interests.

\section{Authors' contributions}

Conception and design: JL, SL, XL. Development of methodology: JL, XL. Analysis and interpretation of data (e.g., statistical analysis, biostatistics, computational analysis): JL, SL, RC, HY, XL. Writing, review, and/or revision of the manuscript: $J$, XL. Study supervision: XL. All authors read and approved the final manuscript.

\section{Acknowledgements}

This work was supported by grants from the Natural Science Foundation of China (No.81172456) and the Natural Science Foundation of Shanghai (No.124119a5502).

\footnotetext{
Author details

'Obstetrics and Gynecology Hospital, Fudan University, Shanghai 200011, China. 2Department of Obstetrics and Gynecology of Shanghai Medical College, Fudan University, Shanghai 200032, China. ${ }^{3}$ Shanghai Key Laboratory of Female Reproductive Endocrine Related Diseases, Shanghai 200011, China. ${ }^{4}$ Department of Biochemistry and Molecular Biology, Key Laboratory of Molecular Medicine, Ministry of Education, Fudan University Shanghai Medical College, Shanghai 200032, China. ${ }^{5}$ Present address: Department of Gynecology,
}

Obstetrics and Gynecology Hospital of Fudan University, No.419, Fangxie Road, Shanghai 200011, China.

Received: 23 January 2015 Accepted: 22 July 2015

Published online: 06 August 2015

\section{References}

1. Coleman RL, Monk BJ, Sood AK, Herzog TJ. Latest research and treatment of advanced-stage epithelial ovarian cancer. Nat Rev Clin Oncol. 2013;10:211-24.

2. Poveda A, Ray-Coquard I, Romero I, Lopez-Guerrero JA, Colombo N. Emerging treatment strategies in recurrent platinum-sensitive ovarian cancer: focus on trabectedin. Cancer Treat Rev. 2014;40:366-75.

3. Lopez J, Banerjee S, Kaye SB. New developments in the treatment of ovarian cancer-future perspectives. Ann Oncol. 2013;24 Suppl 10:x69-76.

4. Albini A, Tosetti F, Li WW, Noonan DM, Li WW. Cancer prevention by targeting angiogenesis. Nat Rev Clin Oncol. 2012;9:498-509.

5. Monk BJ, Dalton H, Farley JH, Chase DM, Benjamin I. Antiangiogenic agents as a maintenance strategy for advanced epithelial ovarian cancer. Crit Rev Oncol Hematol. 2013;86:161-75.

6. Eskander RN, Tewari KS. Incorporation of anti-angiogenesis therapy in the management of advanced ovarian carcinoma-mechanistics, review of phase III randomized clinical trials, and regulatory implications. Gynecol Oncol. 2014;132:496-505

7. Aravantinos $G$, Pectasides D. Bevacizumab in combination with chemotherapy for the treatment of advanced ovarian cancer: A systematic review. J Ovarian Res. 2014;7:57.

8. Pujade-Lauraine E, Hilpert F, Weber B, Reuss A, Poveda A, Kristensen G, et al. Bevacizumab combined with chemotherapy for platinum-resistant recurrent ovarian cancer: The AURELIA open-label randomized phase III trial. J Clin Oncol. 2014:32:1302-8.

9. Aghajanian C, Blank SV, Goff BA, Judson PL, Teneriello MG, Husain A, et al. OCEANS: a randomized, double-blind, placebo-controlled phase III trial of chemotherapy with or without bevacizumab in patients with platinum-sensitive recurrent epithelial ovarian, primary peritoneal, or fallopian tube cancer. J Clin Oncol. 2012;30:2039-45.

10. Perren TJ, Swart AM, Pfisterer J, Ledermann JA, Pujade-Lauraine E, Kristensen $\mathrm{G}$, et al. A phase 3 trial of bevacizumab in ovarian cancer. $N$ Engl J Med. 2011;365:2484-96.

11. Burger RA, Brady MF, Bookman MA, Fleming GF, Monk BJ, Huang $H$, et al. Incorporation of bevacizumab in the primary treatment of ovarian cancer. N Engl J Med. 2011;365:2473-83.

12. Monk BJ, Poveda A, Vergote I, Raspagliesi F, Fujiwara K, Bae DS, et al. Anti-angiopoietin therapy with trebananib for recurrent ovarian cancer (TRINOVA-1): a randomised, multicentre, double-blind, placebocontrolled phase 3 trial. Lancet Oncol. 2014;15:799-808.

13. Karlan BY, Oza AM, Richardson GE, Provencher DM, Hansen VL, Buck M, et al. Randomized, double-blind, placebo-controlled phase II study of AMG 386 combined with weekly paclitaxel in patients with recurrent ovarian cancer. J Clin Oncol. 2012:30:362-71.

14. du Bois A, Floquet A, Kim JW, Rau J, del Campo JM, Friedlander M, et al. Incorporation of pazopanib in maintenance therapy of ovarian cancer. J Clin Oncol. 2014;32:3374-82.

15. Liu JF, Barry WT, Birrer M, Lee JM, Buckanovich RJ, Fleming GF, et al. Combination cediranib and olaparib versus olaparib alone for women with recurrent platinum-sensitive ovarian cancer: a randomised phase 2 study. Lancet Oncol. 2014:15:1207-14.

16. Ledermann JA, Perren T, Raja FA, Embleton A, Rustin GJS, Jayson G, et al. Randomised double-blind phase III trial of cediranib (AZD 2171) in relapsed platinum sensitive ovarian cancer: results of the ICON6 trial. Eur J Cancer. 2013;49 Suppl 3:LBA10.

17. Ledermann JA, Hackshaw A, Kaye S, Jayson G, Gabra H, McNeish I, et al. Randomized phase II placebo-controlled trial of maintenance therapy using the oral triple angiokinase inhibitor BIBF 1120 after chemotherapy for relapsed ovarian cancer. J Clin Oncol. 2011;29:3798-804.

18. Du Bois A, Kristensen G, Ray-Coquard I, Reuss A, Pignata S, Colombo N, et al. AGO-OVAR 12: a randomized placebo-controlled GCIG/ENGOT-intergroup phase III trial of standard frontline chemotherapy+/- nintedanib for advanced ovarian cancer. Int J Gynecol Cancer. 2013;23(Suppl1):LBA1.

19. Gotlieb WH, Amant F, Advani S, Goswami C, Hirte H, Provencher D, et al. Intravenous aflibercept for treatment of recurrent symptomatic malignant 
ascites in patients with advanced ovarian cancer: a phase 2, randomised, double-blind, placebo-controlled study. Lancet Oncol. 2012;13:154-62.

20. Ye Q, Chen HL. Bevacizumab in the treatment of ovarian cancer: a meta-analysis from four phase III randomized controlled trials. Arch Gynecol Obstet. 2013;288:655-66

21. Zhou M, Yu P, Qu X, Liu Y, Zhang J. Phase III trials of standard chemotherapy with or without bevacizumab for ovarian cancer: a meta-analysis. PLoS One. 2013;8:e81858.

22. Lambrechts D, Lenz HJ, de Haas S, Carmeliet P, Scherer SJ. Markers of response for the antiangiogenic agent bevacizumab. J Clin Oncol. 2013;31:1219-30

23. Backen A, Renehan AG, Clamp AR, Berzuini C, Zhou C, Oza A, et al. The combination of circulating Ang1 and Tie2 levels predicts progression-free survival advantage in bevacizumab-treated patients with ovarian cancer. Clin Cancer Res. 2014;20:4549-58.

24. Collinson F, Hutchinson M, Craven RA, Cairns DA, Zougman A, Wind TC, et al. Predicting response to bevacizumab in ovarian cancer: a panel of potential biomarkers informing treatment selection. Clin Cancer Res. 2013;19:5227-39.

25. Slaughter KN, Thai T, Penaroza S, Benbrook DM, Thavathiru E, Ding K, et al. Measurements of adiposity as clinical biomarkers for first-line bevacizumab-based chemotherapy in epithelial ovarian cancer. Gynecol Oncol. 2014;133:11-5.

26. Chase DM, Sill MW, Monk BJ, Chambers MD, Darcy KM, Han ES, et al. Changes in tumor blood flow as measured by Dynamic Contrast-Enhanced Magnetic Resonance Imaging (DCE-MRI) may predict activity of single agent bevacizumab in recurrent epithelial ovarian (EOC) and primary peritoneal cancer (PPC) patients: an exploratory analysis of a Gynecologic Oncology Group Phase II study. Gynecol Oncol. 2012;126:375-80.

27. Chan JK, Kiet TK, Blansit K, Ramasubbaiah R, Hilton JF, Kapp DS, et al. MiR378 as a biomarker for response to anti-angiogenic treatment in ovarian cancer. Gynecol Oncol. 2014;133:568-74.

28. Stockler MR, Hilpert F, Friedlander M, King MT, Wenzel L, Lee CK, et al. Patient-reported outcome results from the open-label phase III AURELIA trial evaluating bevacizumab-containing therapy for platinum-resistant ovarian cancer. J Clin Oncol. 2014;32:1309-16.

\section{Submit your next manuscript to BioMed Central and take full advantage of:}

- Convenient online submission

- Thorough peer review

- No space constraints or color figure charges

- Immediate publication on acceptance

- Inclusion in PubMed, CAS, Scopus and Google Scholar

- Research which is freely available for redistribution 